\title{
Effect of Red Fruit Oil (Pandanus Conoideus Lam) on Animal Model of Preeclampsia
}

\author{
I.W. Sugiritama ${ }^{1}$, I.G.A. Dewi Ratnayanti ${ }^{2}$, I.G.N. Sri Wiryawan ${ }^{3}$, I.A Ika Wahyuniari ${ }^{4}$, N.M. Linawati ${ }^{5}$ \\ I.G.K.N. Arijana ${ }^{6}$ \\ 1,2,3,4,5,6 Udayana University, Faculty of Medicine, Dept. of Histology, Jl. P. B. Sudirman, Denpasar, Indonesia
}

\begin{abstract}
Preeclampsia is a complication of pregnancy with hypertension and proteinuria as major symptomps. Although the pathogenesis of preeclampsia is not yet clear, the role of oxidative stress had been proven by several studies. The role of antioxidants in preventing preeclampsia also had been reported. Red fruit oil (RFO), extracted from red fruit (Pandanus conoideus Lam), is rich in antioxidants vitamin $E$ and $\beta$-carotene. The aims of this study were to investigate the potency of $R F O$ in the prevention of preeclampsia in animal model of preeclampsia. A total of thirty two female Wistar rats on day-1 pregnancy were randomly divided into 4 groups of 8 rats each. To establish the preeclampsia symptoms all groups were given three kinds of stress that were overpopulation, noise and acute stress. Group 1 as a control was given distilled water $0.6 \mathrm{ml} /$ day, group 2, 3, and 4 as treatment groups were given $\mathrm{RFO} 0.15 \mathrm{ml} /$ day, 0.3 $\mathrm{ml} /$ day and $0.6 \mathrm{ml} /$ day respectively. The blood pressure and urine protein were measured before and after treatment, while the plasma Malondialdehide (MDA) levels were measured after treatment. The results showed that were an increase of blood pressure and urine protein level in control group, but not in treatment group. Control group had higher plasma MDA levels compared with all treatment group. There was significant difference between the $M D A$ levels in group 1 with group 2,3 , and $4(P<0.05)$, and there was a positive correlation $(P<0.01)$ in the plasma MDA levels with blood pressure and proteinuria. The results of this study indicate that the $R F O$ can prevent the symptoms of preeclampsia, through its antioxidant activity in animal model of preeclampsia.
\end{abstract}

Keywords: Red Fruit Oil, Preeclampsia, MDA, Antioxidant, Oxidative Stress

\section{Introduction}

Preeclampsia is a multisystem disorder that characterized by new onset of hypertension (blood pressure $\geq 140 / 90 \mathrm{~mm} \mathrm{Hg}$ ) and proteinuria $(>300 \mathrm{mg} / 24 \mathrm{~h}$ ) arising after 20 weeks of gestational age in a previously normotensive woman [1]. Preeclampsia affects $5-10 \%$ of the pregnancies, and is the main cause of mortality and morbidity both mother and fetus [3].

Studies had been done to explain the pathogenesis of preeclampsia, and found that oxidative stress plays an important role $[4,5]$. Oxidative stress occurs in placental and systemic circulation of preeclamptic women. In the placenta, levels of MDA is increased, and the levels of antioxidants SOD, $\beta$-carotene, $\alpha$-tocopherol and gluthatione are decreased[6-8]. In the plasma there are also an increased of oxidative products such as MDA and PGF (2alpha) [9, 10], while the level and activity of antioxidant SOD, $\alpha$ tocopherol, ascorbic acid and $\beta$-carotene are decreased [912]. Oxidative stress in systemic circulation trigger the endothelial dysfunction, which then causes the clinical symptoms of preeclampsia (hypertension and proteinuria) $[13,14]$.

Base on the evidences that oxidative stress plays an important role in the pathogenesis of preeclampsia, antioxidants has potential benefit in the prevention preeclampsia. The effectiveness of antioxidants in preventing preeclampsia remains questionable, though theoretically antioxidants should be able to prevent preeclampsia[15]. Several study found that antioxidants effectively prevent preeclampsia [9, 16, 17], and other studies had opposite result[18-21]. However the potency of antioxidants in preventing preeclampsia continues to be studied. Recently there have been great efforts to find safe and potent natural antioxidants from various plant sources[22]

Red fruit (Pandanus conoideus Lam) grow in Papua province, Indonesia and is traditionally consumed by local communities. Oil extracted from red fruit contains high level of antioxidant vitamin E ( $\alpha$ and $\gamma$-tocopherol)[23], low level $\beta$-carotene[24], and it show antioxidant activity[22]. Due to it's content and activity the (RFO) are potentially use to prevent preeclampsia. Vitamin $\mathrm{E}$ is very potent in prevent preeclampsia because it is the most important fat-soluble antioxidant in preventing lipid peroxidation, and has non antioxidant properties such as: preventing free radical formation, preventing apoptosis of placental tissue, inhibiting activation of the endothelium and leukocytes, and as antiinflammatory which all can play a role in the prevention of preeclampsia $[15,25]$. Beta carotene also has capabilities as an antioxidant, which can strengthen the antioxidant capacity of vitamin $\mathrm{E}[26,27]$.

Research that was conducted to determine the effectiveness of a material in preventing preeclampsia is often hampered by difficulties in doing experimental research, because it is obstructed by the ethical issues and safety of the materials used to the mother and baby. An animal model of preeclampsia which is introduced by Takiuti et al showed symptoms of preeclampsia such as : hypertension, proteinuria and IUGR, that can be used to test the effectiveness of a substance in preventing preeclampsia.[28]

\section{Materials and Methods}

\subsection{Animal}

Thirty two female adult Wistar rats (220-250 g) were used in this study. All rats were maintained under controlled 


\section{International Journal of Science and Research (IJSR) \\ ISSN (Online): 2319-7064}

Index Copernicus Value (2013): 6.14 | Impact Factor (2015): 6.391

condition : $25 \pm 2{ }^{\circ} \mathrm{C}$ temperature, $50 \pm 15 \%$ relative humidity and normal photoperiod (12-hours light-dark cycle). Standard mouse pellet and tap water were provide ad libithum for all animal. To determine the day of pregnancy, the rats were mated separately overnight. If spermatozoa were found in vaginal smear, it is defined as the 0 day of pregnancy

\subsection{Red fruit oil extraction method}

The $P$. conoideus oil was extracted by the method of Folch et al.[20]. A total of $12 \mathrm{~g}$ pulp of the red fruit macerated with $80 \mathrm{ml}$ of fluid consisting of chloroform and methanol (2: 1, v / v). The mixture is stirred with a magnetic stirrer for 1 hour at room temperature. The solution is filtered with a vacuum pump, add $16 \mathrm{ml}$ of $0.88 \% \mathrm{NaCl}$, and the next stage is the separation with separating flask. Red fruit oil extract was then evaporated with a rotary evaporator at $40^{\circ} \mathrm{C}$, packed in dark bottles, dried with nitrogen gas, and stored at $-20^{\circ} \mathrm{C}$ until the time given to rats

\subsection{Experimental Protocol}

The female Wistar rats, on the first day pregnancy were randomly assigned to one of the four groups with 8 rats in each gorup. Control group (Group 1) were given aquadest and three other groups (Group 2, 3 and 4) were given RFO since $7^{\text {th }}$ until $20^{\text {th }}$ days of pregnancy, with a dose of 0.15 $\mathrm{ml} /$ day, $0,3 \mathrm{ml} /$ day, and $0,6 \mathrm{ml} /$ day respectively for groups 2 , 3 and 4 . All groups were given three kinds of stress, that is: (1) overpopulation stress at $7^{\text {th }}$ until $20^{\text {th }}$ days of pregnancy by placing one group of animal ( 8 rats) in a cage with a size of $18 \times 24 \times 25 \mathrm{~cm}$, (2) chronic stress by giving a noise 100 $\mathrm{dB}$ for 30 minutes interspersed by resting for 90 minutes with total of 6 hours a day starting from $7^{\text {th }}$ until $14^{\text {th }}$ days of pregnancy, and (3) acute stress on the $18^{\text {th }}$ day of pregnancy by placing the rat in the tube with $5 \mathrm{~cm}$ diameter and $15 \mathrm{~cm}$ length for 30 minutes.

\subsection{Blood Pressure Measurements}

Blood pressure measurements are performed twice, on the $7^{\text {th }}$ day of pregnancy (prior to administration of RFO and stress) and on the $18^{\text {th }}$ day of pregnancy (after administration acute stress). Blood pressure was measured with a noninvasive sphygmomanometer (models S-2 version 6.90 manufactured by Hugo Sachs Electronic) at the base of the tail of the experimental animals.

\subsection{Urine Protein Levels Measurments}

Measurement of urine protein levels performed twice on $7^{\text {th }}$ and $20^{\text {th }}$ day of pregnancy. Urine protein levels was measured from the urine which is collected in metabolic cages for 24 hours by using a colorimetric test method Pyrogallol red.

\subsection{MDA Measurement}

At $20^{\text {th }}$ pregnancy the blood samples were taken from the orbital sinus by using capillary glass tube for measurement of MDA. Measurement of plasma MDA levels using methods TBARS which measures the concentration of thiobarbituric acid reactive substances.

\section{Results}

ANOVA analysis found no significant difference in systolic blood pressure among the four groups at the $7^{\text {th }}$ day of pregnancy, whereas on day $18^{\text {th }}$ there was a significant difference (figure 1) $(p<0.05)$. Post hoc analysis found a significant difference of sistolic blood pressure among groups 1 and group 2, 3, and $4(\mathrm{p}<0.05)$. Paired t-test analysis found that sistolic blood pressure significantly increased in group 1, while group 2, 3, and 4 did not change significantly $(\mathrm{p}<0.05)$.

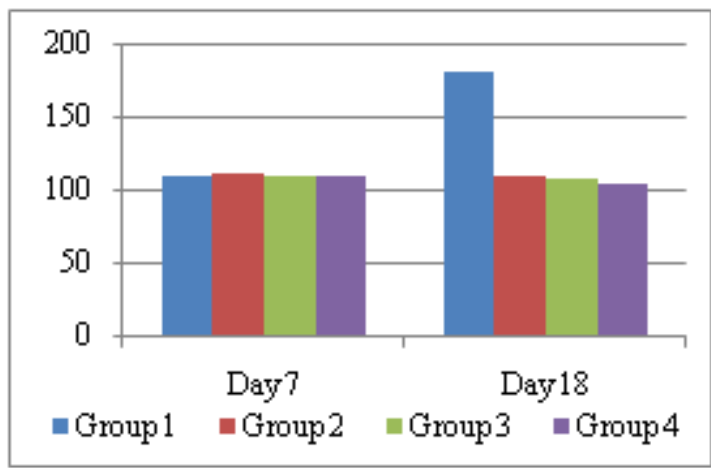

Figure 1: Systolic blood pressure $(\mathrm{mmHg})$ on 7 th and 18th days of pregnancy

Statictical analysis of urine protein level found no significant difference among the four groups at the $7^{\text {th }}$ day of pregnancy, while on the $20^{\text {th }}$ day of pregnancy there was a significant difference (figure 2$)(p<0.05)$. Post hoc analysis found a significant difference in the levels of urine proteins level among groups 1 and group 2, 3, and $4(\mathrm{p}<0.05)$. Paired t-test analysis found that levels of urinary protein significantly increased in group 1, while group 2, 3, and 4 did not change significantly $(\mathrm{p}<0.05)$.

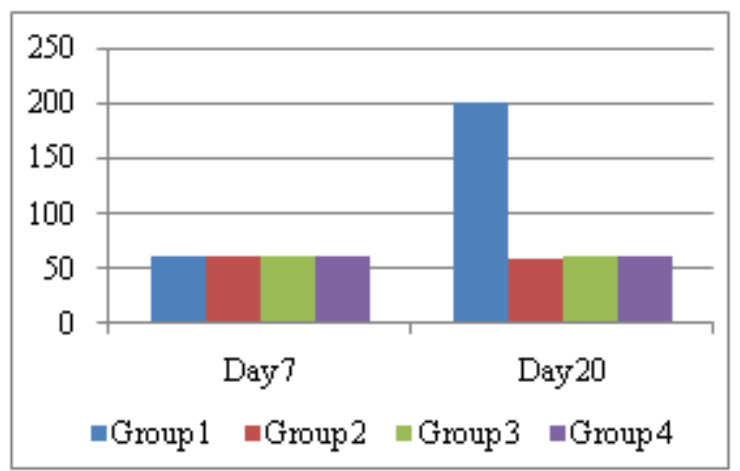

Figure 2: Urine protein level $(\mathrm{mg} / \mathrm{dL})$ on $7^{\text {th }}$ and $20^{\text {th }}$ days of pregnancy

The assay of plasma MDA levels on day $20^{\text {th }}$ of pregnancy found the highest levels of MDA in the control group (figure $3)$. ANOVA analysis found a significant difference between the the four groups $(\mathrm{P}<0,05)$, and post hoc analysis found differences of plasma MDA levels between groups 1 and 2, 3 and 4 and between the group 4 and 1,2 , and $3(P<0,05)$. 


\section{International Journal of Science and Research (IJSR) \\ ISSN (Online): 2319-7064}

Index Copernicus Value (2013): 6.14 | Impact Factor (2015): 6.391

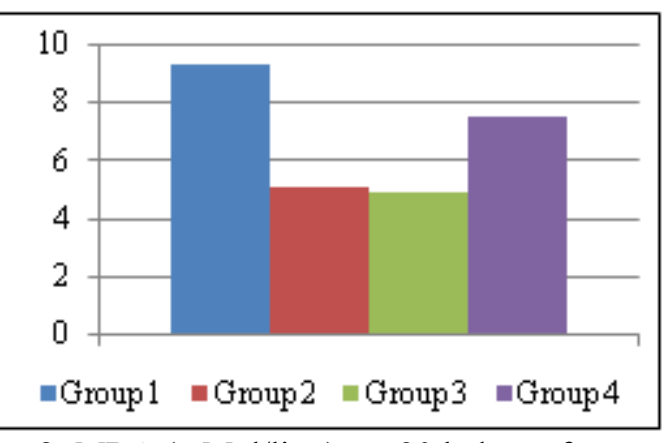

Figure 3: MDA (mMol/liter) on 20th days of pregnancy

Bivariate correlation analysis found a strong positive correlation $(\mathrm{p}<0.01)$ between the blood pressure with proteinuria, and between the plasma MDA levels with blood pressure and proteinuria.

\section{Discussion}

This study has shown the benefits of RFO in preventing preeclampsia and proves it's antioxidant activity. Some previous research have reported potential health benefits of RFO such as lowering blood sugar in diabetic rats [22], increasing anti-inflammatory and immune cells[29], and inhibiting tumor growth and killing cancer cells [30]. The functionality of RFO was due to the content of active compounds such as phenols, carotenoids, and tocopherols [29].

RFO treatment from $7^{\text {th }}$ to $20^{\text {th }}$ day of pregnancies, effectively prevented systolic blood pressure increase and proteinuria animal model of preeclampsia. Thus it can be said that the RFO is able to prevent preeclampsia. The effectiveness of antioxidants in preventing preeclampsia is shown by several studies. Consumption of $1,000 \mathrm{mg}$ of vitamin $\mathrm{C}$ and 400 IU of vitamin $\mathrm{E}$ from 18-22 weeks of pregnancy can significantly reduce the incidence of preeclampsia[9]. Combinations of vitamins $\mathrm{A}$ and $\mathrm{D}$ from cod liver oil with $100 \mathrm{mg}$ vitamin $\mathrm{C}$ and $200 \mathrm{IU}$ of vitamin B1 started at $24^{\text {th }}$ weeks of pregnancy reduce the incidence of preeclampsia in primigravida[16]. Supplementation medical food containing L-arginine and antioxidant vitamins during pregnancy reduced the incidence of preeclampsia [17].

Research using animal model of preeclampsia also found a positive results. Administration of a hydrogen-rich saline attenuated the severity of preeclampsia in the L-NAMEinduced rat model. Hydrogen-rich saline able to buffer the oxidative stress of placenta and prevent its consequent pathological process [31]. Astaxanthin significantly reduced the blood pressure, urine protein, MDA level, and increased the activity of SOD of preeclampsia rats (L-NAME induced rat model)[32]. The results of these study indicated that antioxidant is able to improve the preeclampsia symptoms by effectively reducing the oxidative stress.

The different results was reported by Stratta et al., 1994 with 100-300 mg of vitamin E per day [20] and Gulmezoglu et al., 1997 with $1000 \mathrm{mg}$ of vitamin $\mathrm{C}$ and $800 \mathrm{IU}$ of vitamin $\mathrm{E}$ per day [21]. The failure of this study to prove that antioxidants can prevent preeclampsia is caused by a delay in administration of antioxidants. Antioxidants should start given before 24 weeks of gestation, because the pathophysiology of preeclampsia was started several weeks before clinical symptoms appear [9]. Prevention of preeclampsia with antioxidants should be done as early as possible because lipid peroxidation occur progressively in accordance with increasing gestational age[15]. In this study, RFO can effectively prevent preeclampsia because RFO given prior to oxidative stress (on the 7 th day of pregnancy before the stress was given).

MDA plasma level of treatment group were significantly lower than the control group, it proves that the RFO can prevent oxidative stress in an animal model of preeclampsia. Oxidative stress occurs when the levels of prooxidant are higher than antioxidant. Red fruit oil contains high level antioxidant $\alpha$-tocopherol and $\gamma$-tocopherol [23], low level $\beta$ carotene[24], and has been shown to have antiosidan aktivity [22]. Many studies have shown that vitamin $E$ is very effective against oxidative stress through the mechanism of prevention of lipid peroxidation[33]. Vitamin $\mathrm{E}$ contained in the RFO are very potent in inhibiting oxidative stress, because other than as chain-breaking antioxidants vitamin $\mathrm{E}$ can prevent oxidative stress by preventing the formation of free radicals through inhibition of the enzyme NAD (P) $\mathrm{H}$ oxidase in the placenta and in mother's neutrophils [19], and it also able to prevent the formation of free radicals in mitochondria [33]. The antioxidant capacity of vitamin $\mathrm{E}$ is increased by the presence of $\beta$-carotene in the RFO. Beta-carotene have antioxidant properties in vitro and in animal models. Mixtures of carotenoids with others antioxidants (e.g. vitamin E) can increase their activity against free radicals [27]

RFO can prevent preeclampsia due to its antioxidant activity, as it reduce oxidative stress. It can be seen from the plasma MDA levels were lower in the treatment group compared to the control group and a strong positive correlation $(\mathrm{p}<0.01)$ between plasma MDA level with systolic blood pressure and proteinuria. Many studies conclude that oxidative stress plays a role in the pathogenesis of preeclampsia, which is characterized by an increase of lipid peroxidation products and decreased antioxidant both in the placenta and the systemic circulation [25, 34, 35]. Oxidative stress that occurs in preeclampsia is a known trigger of endothelial dysfunction[15], and almost all experts agree that the symptoms of preeclampsia appear as a result of endothelial dysfunction[36, 37].

\section{Conclusion}

Red Fruit Oil effectively prevent the symptoms of preeclampsia in an animal model of preeclampsia, through it's antioxidant activity in preventing oxidative stress.

\section{References}

[1] Lambert, G., et al., Preeclampsia: an update. Acta Anaesthesiol Belg, 2014. 65(4): p. 137-49.

[2] Sanchez-Aranguren, L.C., et al., Endothelial dysfunction and preeclampsia: role of oxidative stress. Front

\section{Volume 5 Issue 7, July 2016




\section{International Journal of Science and Research (IJSR) \\ ISSN (Online): 2319-7064}

Index Copernicus Value (2013): 6.14 | Impact Factor (2015): 6.391

Physiol, 2014. 5: p. 372.

[3] Uzan, J., et al., Pre-eclampsia: pathophysiology, diagnosis, and management. Vasc Health Risk Manag, 2011. 7: p. 467-74.

[4] Takagi, Y., et al., Levels of oxidative stress and redoxrelated molecules in the placenta in preeclampsia and fetal growth restriction. Virchows Arch, 2004. 444(1): p. 49-55.

[5] Poston, L., M. Raijmakers, and F. Kelly, Vitamin E in preeclampsia. Ann N Y Acad Sci, 2004. 1031: p. 242-8.

[6] Wang, Y.P., et al., The imbalance between thromboxane and prostacyclin in preeclampsia is associated with an imbalance between lipid peroxides and vitamin $E$ in maternal blood. Am J Obstet Gynecol, 1991. 165(6 Pt 1): p. 1695-700.

[7] Wang, Y., S.W. Walsh, and H.H. Kay, Placental lipid peroxides and thromboxane are increased and prostacyclin is decreased in women with preeclampsia. Am J Obstet Gynecol, 1992. 167(4 Pt 1): p. 946-9.

[8] Staff, A.C., et al., Increased contents of phospholipids, cholesterol, and lipid peroxides in decidua basalis in women with preeclampsia. Am J Obstet Gynecol, 1999. 180(3 Pt 1): p. 587-92.

[9] Chappell, L.C., et al., Effect of antioxidants on the occurrence of pre-eclampsia in women at increased risk: a randomised trial. Lancet, 1999. 354(9181): p. 810-6.

[10] Genc, H., et al., Evaluation of oxidative stress markers in first trimester for assessment of preeclampsia risk. Arch Gynecol Obstet, 2011. 284(6): p. 1367-73.

[11] Sagol, S., E. Ozkinay, and S. Ozsener, Impaired antioxidant activity in women with pre-eclampsia. Int $\mathrm{J}$ Gynaecol Obstet, 1999. 64(2): p. 121-7.

[12] Davidge, S.T., et al., Sera antioxidant activity in uncomplicated and preeclamptic pregnancies. Obstet Gynecol, 1992. 79(6): p. 897-901.

[13] Hubel, C.A., Oxidative stress in the pathogenesis of preeclampsia. Proc Soc Exp Biol Med, 1999. 222(3): p. 222-35.

[14] Granger, J.P., et al., Pathophysiology of hypertension during preeclampsia linking placental ischemia with endothelial dysfunction. Hypertension, 2001. 38(3 Pt 2): p. 718-22.

[15] Raijmakers, M.T., R. Dechend, and L. Poston, Oxidative stress and preeclampsia: rationale for antioxidant clinical trials. Hypertension, 2004. 44(4): p. 374-80.

[16] Poston, L. and M.T. Raijmakers, Trophoblast oxidative stress, antioxidants and pregnancy outcome--a review. Placenta, 2004. 25 Suppl A: p. S72-8.

[17] Vadillo-Ortega, F., et al., Effect of supplementation during pregnancy with L-arginine and antioxidant vitamins in medical food on pre-eclampsia in high risk population: randomised controlled trial. BMJ, 2011. 342: p. d2901.

[18] Polyzos, N.P., et al., Combined vitamin $C$ and $E$ supplementation during pregnancy for preeclampsia prevention: a systematic review. Obstet Gynecol Surv, 2007. 62(3): p. 202-6.

[19] Salles, A.M., et al., Antioxidants for preventing preeclampsia: a systematic review. ScientificWorldJournal, 2012. 2012: p. 243476.

[20] Stratta, P., et al., Vitamin E supplementation in preeclampsia. Gynecol Obstet Invest, 1994. 37(4): p.
246-9.

[21] Gulmezoglu, A.M., G.J. Hofmeyr, and M.M. Oosthuisen, Antioxidants in the treatment of severe preeclampsia: an explanatory randomised controlled trial. Br J Obstet Gynaecol, 1997. 104(6): p. 689-96.

[22] Rohman, A., Riyanto, S., Yuniarti, N., Saputra, W. R.,Utami, R. and Mulatsih, W, Antioxidant activity, total phenolic, and total flavaonoid of extracts and fractions of red fruit (Pandanus conoideus Lam). International Food Research Journal, 2010. 17: p. 97-106.

[23] Sarungallo, Z.L., Hariyadi,P., Andarwulan,N., and Purnomo,E.H., Characterization of Chemical Properties, Lipid Profile, Total Phenol and Tocopherol Content of Oils Extracted from Nine Clones of Red Fruit (Pandanus conoideus). Kasetsart J. (Nat. Sci.) 2015. 49: p. 237 - 250.

[24] Sarungalloa, Z.L., Hariyadia,P., Andarwulana,N., Purnomo,E.H., and Wadad,M., Analysis of $\alpha$ cryptoxanthin, $\beta$-cryptoxanthin, $\alpha$-carotene, and $\beta$ carotene of Pandanus conoideus oil by highperformance liquid chromatography (HPLC). Procedia Food Science, 2015. 3: p. 231 - 243.

[25] Takacs, P., et al., Increased circulating lipid peroxides in severe preeclampsia activate NF-kappaB and upregulate ICAM-1 in vascular endothelial cells. FASEB J, 2001. 15(2): p. 279-81.

[26] Young, I.S. and J.V. Woodside, Antioxidants in health and disease. J Clin Pathol, 2001. 54(3): p. 176-86.

[27] Paiva, S.A. and R.M. Russell, Beta-carotene and other carotenoids as antioxidants. J Am Coll Nutr, 1999. 18(5): p. 426-33.

[28] Takiuti, N.H., S. Kahhale, and M. Zugaib, Stress in pregnancy: a new Wistar rat model for human preeclampsia. Am J Obstet Gynecol, 2002. 186(3): p. 544-50.

[29] Surono, I., T.A. Endaryanto and T. Nishigaki., Indonesian biodiversities from microbes to herbal plants as potential functional foods. J. Fac. Agric. Shinshu Univ, 2008. 44(1.2): p. 23-27.

[30] Mun'im, A., R. Andrajati and H. Susilowati, Inhibitions of test tumorigénesis of red fruits (Pandanus conoideus L.) extract against female Sprague-Dawley rats induced dimetilbenz 7.12 (a) anthracene (DMBA). Indonesia J. Pharm. Sci., 2006. 3.

[31] Yang, X., et al., Protective effects of hydrogen-rich saline in preeclampsia rat model. Placenta, 2011. 32(9): p. 681-6.

[32] Xuan, R.-r., et al., [Effect of astaxanthin on preeclampsia rat model]. Yao Xue Xue Bao, 2014. 49(10): p. 1400-5.

[33] Brigelius-Flohe, R. and M.G. Traber, Vitamin E: function and metabolism. FASEB J, 1999. 13(10): p. 1145-55.

[34] Walsh, S.W., et al., Placental isoprostane is significantly increased in preeclampsia. FASEB J, 2000. 14(10): p. 1289-96.

[35]Moretti, M., et al., Increased breath markers of oxidative stress in normal pregnancy and in preeclampsia. Am J Obstet Gynecol, 2004. 190(5): p. 1184-90.

[36] Roberts, J.M., et al., Preeclampsia: an endothelial cell disorder. Am J Obstet Gynecol, 1989. 161(5): p. 1200-4.

[37] 37.Lyall, F. and I.A. Greer, The vascular endothelium in normal pregnancy and pre-eclampsia. Rev Reprod, 1996. 1(2): p. 107-16. 